\title{
Mali: women and war
}

How do women see their role in conflict prevention and management? This was the subject of a seminar held in Bamako at the end of March 1996 which brought together about 20 members of the National Women's Movement for Peace and National Unity and representatives of the ICRC.

An increasing number of women in Mali are seeking to become more fully involved in the life of their country. The movement was established with a view to increasing women's motivation and encouraging their participation in dealing with the Tuareg problem in the north. Women can fulfil a vital role in maintaining social cohesion among various ethnic groups and promoting acceptance of cultural diversity. The members of the women's movement expressed the wish to learn more about international humanitarian law; during the seminar the ICRC explained that under this law women, whether combatants or not, are entitled to special protection.

Discussions centred on the importance of listening to the other person's point of view, the need to take due account of resentment caused by social inequalities, the sensitive issue of rape in armed conflict and its consequences for the victim. The participants felt that they had a role to play in consolidating peace and dealing with the aftermath of the conflict, since they are so close to reality and, as wives and mothers, they offer advice and act as a moderating force in their everyday environment. The dialogue and exchange of information between the women's movement and the ICRC will continue.

ICRC News $96 / 15$ 